\title{
BMJ Open Stated preferences for family doctor contract services: a survey of the rural elderly in Anhui Province, China
}

\author{
Cuilian Wang, ${ }^{1,2}$ Yuanyuan Gu, ${ }^{3}$ Linhai Zhao, ${ }^{1}$ Youran Zhang, ${ }^{1}$ Rui Zhou, ${ }^{1}$ \\ Megan $\mathrm{Gu},{ }^{3}$ Lidan Wang (i) ${ }^{1,4}$
}

To cite: Wang C, Gu Y,

Zhao L, et al. Stated

preferences for family doctor

contract services: a survey

of the rural elderly in Anhui

Province, China. BMJ Open

2022;12:e053277. doi:10.1136/

bmjopen-2021-053277

- Prepublication history and additional supplemental material for this paper are available online. To view these files, please visit the journal online (http://dx.doi.org/10.1136/ bmjopen-2021-053277).

CW and YG contributed equally.

Received 09 May 2021

Accepted 03 February 2022

Check for updates

(C) Author(s) (or their employer(s)) 2022. Re-use permitted under CC BY-NC. No commercial re-use. See rights and permissions. Published by BMJ.

${ }^{1}$ School of Health Service and Management, Anhui Medical University, Hefei, Anhui, China ${ }^{2}$ Stomatologic Hospital and College, Anhui Medical University, Hefei, Anhui, China ${ }^{3}$ Centre for the Health Economy, Macquarie University, Sydney, New South Wales, Australia

${ }^{4}$ Center for Health Policy Research, Anhui Medical University, Hefei, Anhui, China

Correspondence to

Lidan Wang;

wanglidan@ahmu.edu.cn

\section{ABSTRACT}

Objective A number of factors contribute to the utilisation of family doctor contract services (FDCS) in China. This study aims to measure the preferences of the elderly for the FDCS and identify the key factors (and their relative importance) that may guide policymakers in more accurately providing the FDCS.

Participants and methods A discrete choice experiment was performed to elicit the preferences for FDCS among the rural elderly in China. Attributes and levels were established based on qualitative methods. Four attributes were included: service type, service package, physician's reputation and annual contract costs. A D-efficient design was used to create a set of profiles that represented FDCS. The survey was conducted face to face using a sample of participants aged 60 and above in rural areas of Anhui Province. The data were analysed using a latent class logit (LCL) model.

Results A total of 545 valid questionnaires were included in the analysis. The average age of the participants was 69.44 (SD 5.80). Two latent classes were identified with the LCL model. All four attributes proved statistically significant at the level of both the population mean and the two classes. The rural elderly showed a preference for FDCS with a relatively good reputation, lower annual contract costs, the basic service with the add-on of chronic disease service and home visit. Age, gender, education, self-reported health status and the number of chronic diseases were found to be associated with latent class membership.

Conclusion In this study, the physician's reputation had the largest impact on the rural elderly's choice of FDCS. Policy recommendations included the need to strengthen family doctor team training, devote greater attention to improving the family doctor's medical skills and service approaches, and increased FDCS efficiency for the care of the rural elderly.

\section{INTRODUCTION}

To achieve efficient and quality care, a multitiered healthcare system is widely adopted around the world with primary care as the first point of contact for people in need of healthcare. ${ }^{1}$ In China, the general population is free to choose healthcare facilities without being restricted by a gatekeeping mechanism. However, residents prefer to seek

\section{Strengths and limitations of this study}

The first study to examine patient preferences for the contents of services within the family doctor contract services scheme.

- A carefully designed and implemented discrete choice experiment to generate reliable preference data from a vulnerable group in China.

- Possible hypothetical bias and data quality issues caused by fatigue and cognitive constraints.

- Results only representative of the rural region of Anhui province.

care in secondary or tertiary hospitals rather than in primary care facilities. This is despite primary care facilities providing care that is usually more accessible and less costly. ${ }^{2}{ }^{3}$ In the health system in China, primary care facilities consist of township hospitals and village clinics in rural areas.

To strengthen primary care facilities and direct patients to the primary medical institutions for treatment, the Chinese government proposed to establish a hierarchical diagnosis and treatment system in a new round of medical reform in 2009. And the family doctor contract services (FDCS) scheme was established in June 2016 to strengthen the gatekeeping mechanism. The target groups of FDCS included the general and priority population which includes the elderly, women, children and patients with chronic diseases. Residents voluntarily sign a contract with a chosen family doctor team, and in turn receive treatment and primary healthcare services in a community setting. This family doctor team consists of general practitioners, nurses and public health workers. The contract is of 1 year duration with its fee charged annually according to the chosen services. Part of the contract is covered by the government, thus the annual contract fee varied from region to region depending on the financial revenue of the regional government. Following the 
implementation of this national policy, 200 model cities were initially selected to implement a pilot programme of FDCS in 2016, and then the programme was expanded to more cities. The government increased financial investment in primary care facilities to facilitate the implementation of the FDCS.

By 2017, the contract sign-up rates for the general and priority groups had reached $35 \%$ and $65 \%$, respectively. ${ }^{5}$ While these numbers are not low, evidence suggested that patients had not been successfully redirected from high-level hospitals to primary care as intended by the policy. ${ }^{56}$ A study found that $70 \%$ of the respondents preferred tertiary hospitals over family doctor for firstcontact care. ${ }^{6}$ Reluctance of patients to visit family doctor has been a significant obstacle to the success of FDCS and the promotion of primary care. ${ }^{3}$

In order to effectively implement FDCS, it is important to understand how Chinese patients feel about FDCS from a consumer perspective. There has been a growing number of studies on consumer preferences for the attributes of primary care services in China. ${ }^{27-9}$ The general finding is that, when choosing primary care facilities, Chinese patients value the quality and attitude of doctors, out-of-pocket costs, travel time, total visit time, etc. These results cannot be directly transferred to the case of FDCS as it is a primary care service in the form of contract with specific types of services agreed on signing. The research on FDCS has been focused on its implementation ${ }^{10-14}$ and policy impact. ${ }^{15-18}$ There is also a small number of studies on the association between patient characteristics and usage of FDCS. ${ }^{19} 20$ Only one study elicited consumer preference for the attributes of FDCS by undertaking a discrete choice experiment (DCE) with 609 rural residents in Shandong Province, China. ${ }^{21}$ However, it did not include any attribute related to the contents of the services such as type of services and the service packages.

The DCE method has been used extensively to evaluate patient choice within healthcare systems. ${ }^{22}{ }^{23}$ It is a technique for eliciting stated preferences, using hypothetical scenarios with products (or services) described by various attributes and levels, and asks respondents to choose their most preferred. The method is particularly useful when evaluating policy within markets with restricted choice, and where the characteristics driving real choices are not observed or attributes of interest are not measured or lack variation (eg, the price in the real market often does not vary much within a period of time). Moreover, estimates are not affected by confounding factors given they are extracted from a controlled experiment. These advantages of DCEs well suited the objectives of this research.

In this study, we undertook a DCE to elicit patient preferences for the attributes associated with FDCS among the rural elderly in Anhui province, China. While the FPCS programme aims for full population coverage, at the current stage, the focus is the priority groups primarily including the elderly and those with chronic conditions. These two groups also largely overlap each other. In Anhui province, where our study was carried out, over

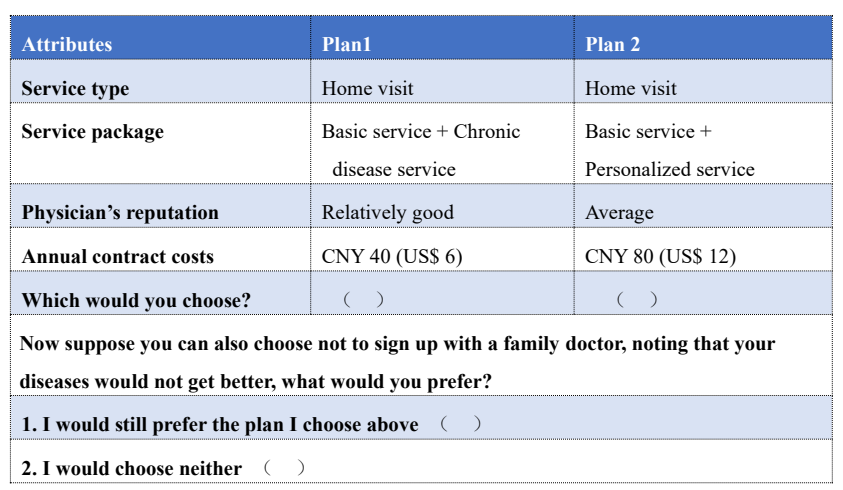

Figure 1 An example of one choice set used in the discrete choice experiment.

90\% of the people who signed up the programme fell into these two groups. Other priority groups are pregnant women and women in childbed, and children with likely different care needs. To design a DCE with attributes that are general enough to accommodate the care needs from all the groups is both challenging and also less useful in helping design targeted policies. We therefore focused on elderly people in this study.

We aimed to answer three questions: (1) what factors affect patient choice to use FDCS?; (2) what is the relative importance between these factors? and (3) how much are they willing to pay for a desirable feature of the FDCS? The findings have important implications for policymakers aiming to improve the utilisation of FDCS and the delivery of precision healthcare services for the elderly in China.

\section{METHODS}

\section{Discrete choice experiment design}

The DCE approach has been widely adopted in eliciting patient preference in healthcare. ${ }^{24}{ }^{25}$ We selected the attributes and their corresponding levels through a systematic review of journal articles and policy documents about FDCS as well as expert consultations (experts in the field of health economics and primary healthcare research). ${ }^{26}{ }^{27}$ Four attributes were included in the final DCE (figure 1): the first is 'service type', representing the type of medical services provided by the family doctor to the elderly, including clinic visit and home visit. The second is 'service package', representing the content of the services, including four levels: basic service, basic service and chronic disease service, basic service and traditional Chinese medicine (TCM) service, and basic service and personalised service. The third is 'physician's reputation' which refers to the residents' evaluation of the skill level, service attitude and quality of the family doctor team. The levels of this attribute include relatively good, average and relatively poor. The fourth is annual contract costs, representing the out-of-pocket cost for signing up to the contract. It is a relatively small component of the total costs which are mainly covered by the government. 
The levels include CNY 20 (US\$ 3), CNY 40 (US\$ 6), CNY 60 (US\$ 9) and CNY 80 (US\$ 12); the average annual exchange rate between US\$ and CNY in 2019 was US\$ $1=\mathrm{CNY} 6.908{ }^{28}$ The levels chosen in our study reflect the actual contract costs in those rural regions where we sampled. A detailed explanation of attributes and levels (online supplemental eTable 1) and service packages (online supplemental eTable 2) as well as the final questionnaire are in the online supplemental document.

The number of attributes and levels $\left(4^{2} \times 3^{1} \times 2^{1}\right)$ was deemed impractical for a full-factorial design due to a large number of choice tasks. ${ }^{29}$ Therefore, we used the Ngene software (V. 1.1.2, ChoiceMetrics) to create an efficient design that maximised the D-efficiency. ${ }^{27}$ An opt-out option was included for each choice set. Compared with those that do not present an opt-out option, DCE that have opt-out options have resulted in a lower risk of overestimating attribute influence. ${ }^{30}$ Respondents were asked to choose plan 1, plan 2, or the opt-out option.

To test the respondents' comprehension of the task and assess the validity of the questionnaire, one rationality test choice set was added. In the test choice set, plan 2 is dominated by plan 1 across all attributes. The respondent was considered to have failed the test if they did not choose the plan $1 .{ }^{31}$ Multiple versions of the questionnaire were generated, each with a computer-generated random sequence of the choice sets. To test the quality and feasibility of the questionnaire, we conducted a pilot test of 50 volunteers in a community to test the understanding, and the validity of the questionnaire content as well as the time it takes to complete the questionnaire. In the pilot, we considered one additional attribute called 'diagnosis and treatment time' and there were eight choice sets. While the participants could understand the choice tasks well, it turned out to be difficult for them to trade-off across five attributes and some also found it cognitively demanding to complete eight choice sets (plus the testing one). We therefore decided to drop the 'diagnosis and treatment time' attribute which was considered the least important attribute by most participants in the pilot and to reduce the number of choice sets from eight to six. We made some other minor adjustments on wording based on the feedback from the pilot testing. Face-to-face interviews with participants were used for both pilot tests and formal data collection.

\section{Data collection}

This study was conducted in Anhui Province, located in the southeast of China. The province has a population of over 63 million and the majority of the residents are middle-or-lower income earners. Multistage random sampling was used to choose a representative sample of the rural elderly population in Anhui which is traditionally divided into three geographical areas: the northern, central and southern region (figure 2). We first randomly selected three cities, Fuyang, Lu'an and Xuancheng, from each region, and then randomly selected a county from each city: Yingzhou, Jin'an and Jingxian. According

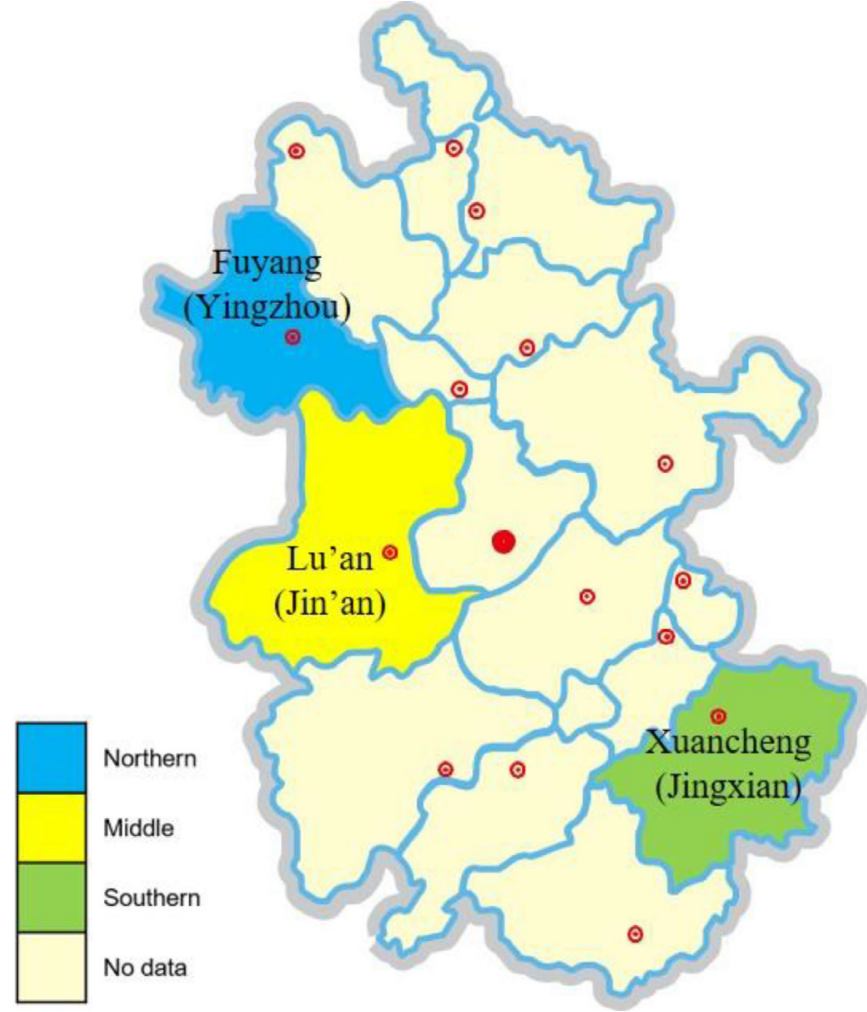

Figure 2 Locations of sampling.

to the sample size requirement of DCE studies, we aimed for around 200 respondents in each county. We did so by randomly choosing two villages in Yingzhou (a relatively populous county), four villages in Jin'an, and four villages in Jingxian. Respondents were eligible for our study if they: (1) were over 60 years old; (2) had spent more than 6 months in the current year at the registered place of residence and (3) could complete the questionnaire independently. From July to August in 2019, a team of trained postgraduate students from Anhui Medical University visited the chosen ten villages. With the help of the village committee, eligible respondents were identified and face-to-face interviews were conducted either at the village committee office or at the respondent's home. At the start of an interview, respondents were told that their participation were completely voluntary, and they were allowed to leave the interview at any time.

When selecting the interviewers, we chose the students from the local counties where data would be collected since they can communicate with the elderly residents using the local dialect. A standard interview manual was used in the training workshop where the selected students were paired to simulate the interview process (one student played the role of the interviewer while the other the interviewee). These students had another chance to practice at the pilot stage when the interview manual was also updated.

The interview manual mainly included: (1) the introduction about the FDCS programme, (2) the explanation on the types of services to be provided after signing the contract, (3) the structure of the questionnaire and the 
detailed definition of each attribute of the DCE and (4) instructions on how to help participants understand the choice task through the warm-up exercise. The manual also explained the interview steps and the order of the choice sets to be presented. There were instructions on terminating the interview if it was clear that the participant could not understand the choice tasks or found it difficult to complete the choice tasks.

The participants were instructed to answer the survey questions carefully as each of their choices would contribute to the development of relevant FDCS policies (this is a 'cheap talk' approach to engage the participants). ${ }^{32}$ Sociodemographic information was also collected including: age, gender, education, marital status, household composition, self-reported health status and the number of chronic diseases.

\section{Statistical analysis}

DCE data were analysed based on random utility theory, where the utility that respondent $i$ derives from choosing alternative $j$ in choice set $t$ is given by

$$
U_{i j t}=X_{i j t} \beta_{i}+\varepsilon_{i j t} ; i=1, \ldots, 545 ; j=1,2,3 ; t=1, \ldots, 6
$$

where $\beta_{i}$ is a vector of coefficients, and $X_{i j t}$ is a vector of variables representing attributes of alternative $j$. If the random term $\varepsilon_{i j t}$ is assumed to be independently and identically distributed according to the type I extreme value distribution, then the model becomes the conditional logit (CLOGIT). The latent class logit (LCL) model was also used to explore the preference heterogeneity among the respondents. ${ }^{33}$ It provided a framework for understanding the latent segmentation of respondent preferences. The number of classes was determined based on the Bayesian Information Criterion (BIC). ${ }^{34}$ Both models were estimated using the Stata software (V. 16 , StataCorp). ${ }^{35}$ Statistical significance was set at $\alpha=0.05$.

The attribute 'cost' was analysed as a continuous variable and other attributes were included as dummy variables due to their categorical nature. Under the LCL model, we estimated preference coefficients for each class and then produced their weighted average over classes as the overall population mean. A positive regression coefficient suggested that respondents preferred an increased value for an attribute, whereas a negative coefficient suggested that respondents preferred a decreased value for an attribute.

We calculated the relative importance (RI) of each attribute as the proportion of the sum of its utility ranges to obtain an understanding of the difference each attribute could represent in the total utility of the programme design. ${ }^{36}$ The formula is as follows:

$$
R I_{k}=\left(\frac{A_{k}}{\sum_{k=1}^{4} A_{k}}\right) \times 100 \%
$$

where $A_{k}$ is the difference between the highest and lowest score among attributes for the $k$ th attribute. We then estimated the mean RI for each class and the population mean.
We also derived the relative value attached to each attribute, which is potentially useful for pricing policymaking because it measures respondents' willingness to pay (WTP) for a desirable feature of the service. ${ }^{37}$ We derived WTP as the negative ratio of the non-cost attribute coefficient to the contract costs coefficient.

A posterior analysis was undertaken to know who the respondents are in a specific class. ${ }^{35}$ We estimated the posterior probability of respondent $i$ for each class by using the Bayes rule. A multinomial logit (MNL) model was estimated to describe each class using individual characteristics. The covariates used in the classes' characterisation are documented in the supplement file (online supplemental eTable 3). After the MNL regression, the average marginal effect for each variable was estimated for each class. Finally, we produced a profile of membership in each class by estimating the expected values of the statistically significant predictors in the membership function. $^{38}$

\section{Patient and public involvement}

Patients were the participants in this study, and not involved in creating the survey instrument in this study.

\section{RESULTS}

\section{Sample characteristics}

The questionnaire was administered to 612 elderly residents, among which 12 were urban dwellers living in the village at the time of data collection, 44 were incomplete and 11 failed the rationality test. A total of 545 questionnaires were included in the analysis (table 1). The average age of the participants was $69.44 \pm 5.80$ years. A slight majority (53.03\%) of them were male. A little more than half of the respondents had an education level of primary school or above $(58.53 \%)$. The vast majority of the respondents $(77.06 \%)$ were married and $55.96 \%$ of all the participants lived with spouses. A little more than one-third $(32.48 \%)$ and only $4.04 \%$ of respondents indicated that they were healthy or very healthy respectively on the day of the survey. A total of $70.83 \%$ of the respondents reported to have at least one chronic disease.

\section{Preferences}

LCL dominated CLOGIT estimates (online supplemental eTable 4) based on BIC, so only the former results are reported. A two-class LCL model was chosen based on $\mathrm{BIC}$ and its estimates were reported in table 2. Class 1 accounted for $83.1 \%$ and class 2 for $16.9 \%$ of the population. Apart from the service package attribute in class 2 , all four attributes were statistically significant in each class. Those in class 1 prioritised service package and annual contract costs more than class 2 . By contrast, those in class 2 gave greater priority to service type and physician's reputation.

The total sample and both classes preferred home visit as opposed to clinic visit, a 'relatively good' physician's reputation and lower contract costs. The population mean 
Table 1 Sample demographic characteristics $(n=545)$

N (\%)/mean (SD)

\begin{tabular}{|c|c|}
\hline Age (in years) & $69.44(5.80)$ \\
\hline \multicolumn{2}{|l|}{ Gender } \\
\hline Male & $289(53.03)$ \\
\hline Female & $256(46.97)$ \\
\hline \multicolumn{2}{|l|}{ Education } \\
\hline No school education & $226(41.47)$ \\
\hline Primary school & $217(39.82)$ \\
\hline Junior high school or above & $102(18.71)$ \\
\hline \multicolumn{2}{|l|}{ Marital status } \\
\hline Married & $420(77.06)$ \\
\hline Other ${ }^{*}$ & $125(22.94)$ \\
\hline \multicolumn{2}{|l|}{ Household } \\
\hline Single & $86(15.78)$ \\
\hline Spouse only & $305(55.96)$ \\
\hline Othert & $154(28.26)$ \\
\hline \multicolumn{2}{|l|}{ Self-reported health status } \\
\hline Very unhealthy & $20(3.67)$ \\
\hline Unhealthy & $187(34.31)$ \\
\hline Moderately healthy & $139(25.5)$ \\
\hline Healthy & 177 (32.48) \\
\hline Very healthy & $22(4.04)$ \\
\hline \multicolumn{2}{|l|}{ Number of chronic diseases } \\
\hline 0 & $159(29.17)$ \\
\hline 1 & $196(35.96)$ \\
\hline 2 & $107(19.63)$ \\
\hline$\geq 3$ & $83(15.23)$ \\
\hline \multicolumn{2}{|l|}{ Region } \\
\hline Yingzhou, Fuyang (north) & $197(36.15)$ \\
\hline Jin'an, Lu'an (central) & 176 (32.29) \\
\hline Jingxian, Xuancheng (south) & $172(31.56)$ \\
\hline
\end{tabular}

${ }^{*}$ Other marital status includes unmarried, widowed and divorced. †Other household members include children only or spouse and children.

and class 1 preferred the service package that included an add-on of the chronic disease service to the basic service.

\section{Relative importance}

We derived the RI for each attribute for the population and the two classes (figure 3). For the population, physician's reputation was the most influential attribute. The second was annual contract costs. Service type was the least important. Class 1 was the same as the mean population. Class 2 regarded physician's reputation as the most important and service package proved the least important.

\section{Willingness to pay}

We also estimated WTP for each attribute level (table 2). On average, respondents were willing to pay CNY 29 (US\$
4) more for a 'home visit' than a 'clinic visit'. They also were willing to pay CNY 45 (US\$ 7) more for a 'basic service with chronic disease service', CNY 20 (US\$ 3) more for a 'basic service with TCM service' and CNY 27 (US\$ 4) more for a 'basic service with personalised service' than the 'basic service'. Moreover, they were willing to pay an additional CNY 55(US\$ 8) for a physician with 'average' reputation and CNY 108(US\$16) for one with 'relatively good' reputation than a physician with a 'relatively poor' reputation.

\section{Class membership profile}

We reported the results in the form of average marginal effects for ease of interpretation (online supplemental eTable 5). The results suggested that age, gender, education, self-reported health status and the number of chronic diseases were statistically significant predictors of class membership. Respondents who were older than 65 , male, with a lower education level, self-reported to be 'healthy', and with less than one chronic disease were more likely to be assigned to class 1 . The expected values for the five significant predictors are in figure 4 .

\section{DISCUSSION}

The underuse of primary care services has become one of the major challenges the Chinese healthcare system is facing today. While the FDCS proposed in 2016 seems promising, patients still preferred visiting high-level hospitals even for mild diseases. Understanding patient preference for the attributes associated with FDCS is therefore important as this allows us to make more informed policy design to provide more effective basic health services and guide residents to the primary health service institutions. To this aim, this study carried out a DCE survey to examine elderly residents' preferences for FDCS.

Our results suggested that all four attributes (service type, service package, physician's reputation and annual contract costs) had a significant impact on patient choice. The rural elderly most valued the physician's reputation, defined as the competence and attitude of family doctors. This finding is consistent with previous non-DCE studies which reported that patients preferred doctors from secondary or tertiary hospitals because they believed that they possess greater skills than those from primary care clinics. ${ }^{39}$ It is also in line with another DCE study of FDCS conducted in rural area of Shandong Province which included two attributes measuring competence and attitudes of doctors separately. ${ }^{21}$

The annual contract cost was the second most important attribute. As reported in a study that the importance of out-of-pocket was ranked next to the travel time in the severe health state scenario. ${ }^{9}$ The Shandong DCE study also suggested that increasing the contract cost would significantly decrease the willingness to sign a contract with the family doctor team. ${ }^{21}$

Our study is the first to examine the patient preferences for the service contents of the FDCS. The rural 
Table 2 The two-class latent class logit model estimates and willingness to pay

\begin{tabular}{|c|c|c|c|c|c|c|c|}
\hline & & \multicolumn{2}{|c|}{ Class 1} & \multicolumn{2}{|c|}{ Class 2} & \multicolumn{2}{|c|}{ Mean preference } \\
\hline & & Est & SE & Est & SE & Est & SE \\
\hline Share & & $0.831^{\star \star \star}$ & 0.019 & $0.169^{\star \star \star}$ & 0.019 & & \\
\hline Asc2 & & $2.649^{* \star *}$ & 0.477 & $-2.248^{\star \star *}$ & 0.415 & $1.823^{\star \star *}$ & 0.397 \\
\hline Service type & Clinic visit† & & & & & & \\
\hline \multirow{2}{*}{ Service package } & $\begin{array}{l}\text { Basic service+chronic } \\
\text { disease service }\end{array}$ & $1.183^{\star \star \star}$ & 0.151 & 0.575 & 0.408 & $1.081^{\star \star *}$ & 0.145 \\
\hline & $\begin{array}{l}\text { Basic } \\
\text { service+traditional } \\
\text { Chinese medicine } \\
\text { service }\end{array}$ & $0.442^{*}$ & 0.257 & 0.522 & 0.328 & $0.455^{\star \star}$ & 0.216 \\
\hline \multirow{3}{*}{$\begin{array}{l}\text { Physician's } \\
\text { reputation }\end{array}$} & Relatively poor† & & & & & & \\
\hline & Average & $1.148^{\star \star \star}$ & 0.441 & $1.580^{\star \star \star}$ & 0.343 & $1.221^{\star \star \star}$ & 0.364 \\
\hline & Relatively good & $2.404^{\star \star \star}$ & 0.405 & $2.696^{\star \star \star}$ & 0.301 & $2.454^{\star \star \star}$ & 0.332 \\
\hline $\begin{array}{l}\text { Annual contract } \\
\text { costs }\end{array}$ & & $-0.025^{\star \star \star}$ & 0.006 & $-0.016^{\star \star}$ & 0.006 & $-0.023^{\star \star \star}$ & 0.005 \\
\hline \multicolumn{8}{|l|}{$\begin{array}{l}\text { Willingness to pay } \\
\text { (CNY)§ }\end{array}$} \\
\hline \multirow[t]{2}{*}{ Service type } & Clinic visit† & & & & & & \\
\hline & Home visit & $25.192^{\star \star}$ & 11.463 & $47.935^{\star \star}$ & 24.389 & $29.029^{\star \star}$ & 9.914 \\
\hline Service package & $\begin{array}{l}\text { Basic } \\
\text { service+personalised } \\
\text { service }\end{array}$ & $26.769^{*}$ & 13.808 & 28.440 & 21.792 & $27.051^{\star \star}$ & 12.079 \\
\hline \multirow{3}{*}{$\begin{array}{l}\text { Physician's } \\
\text { reputation }\end{array}$} & Relatively poor $†$ & & & & & & \\
\hline & Average & $45.969^{*}$ & 24.567 & $98.501^{\star \star}$ & 46.602 & $54.831^{\star \star}$ & 21.103 \\
\hline & Relatively good & $96.258^{\star \star}$ & 31.002 & $168.066^{\star \star}$ & 66.766 & $108.373^{\star \star \star}$ & 27.03 \\
\hline
\end{tabular}

${ }^{* * *} p<0.01 ;{ }^{* *} p<0.05 ;{ }^{*} p<0.1$

†Reference.

$\ddagger$ Weighted average of coefficients over two classes.

$\S$ According to the Organization for Economic Co-operation and Development (OECD) data (https://data.oecd.org/conversion/exchange-rates.htm),

the average annual exchange rate between US\$ and CNY in 2019 was: US\$ 1 = CNY 6.908, Accessed 30 March 2021.

elderly preferred services for chronic diseases over personalised services. Many studies have indicated that the family doctor system has been effective in the management of chronic diseases as it provides continuous, personalised and comprehensive services in addition to integrated prevention and treatment. ${ }^{40-42}$ Over $70 \%$ of the participants in our study suffered from at least one chronic disease. Furthermore, the rural elderly have had a low education level, which often complicates the understanding and acceptance of an appropriate combination of personalised services. ${ }^{43}$ The majority of the participants in this study did not choose TCM service over other services package, despite its proven effectiveness for the cure and treatment of chronic disease in other studies. ${ }^{44}$ Therefore, an argument could be made for the need to offer an additional chronic disease service to the basic service. 
Class 1

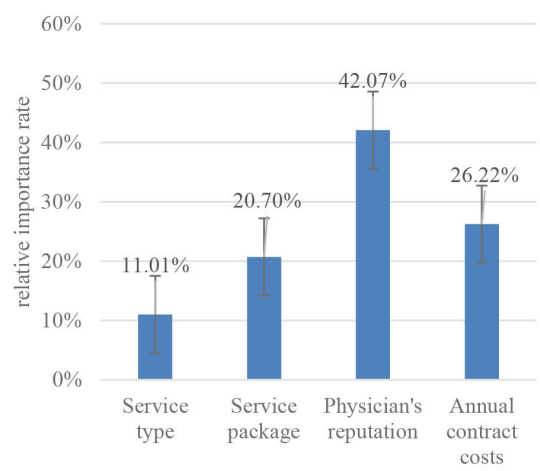

Class 2

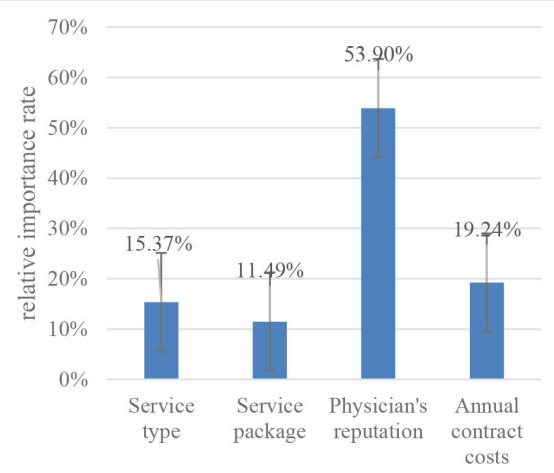

Mean

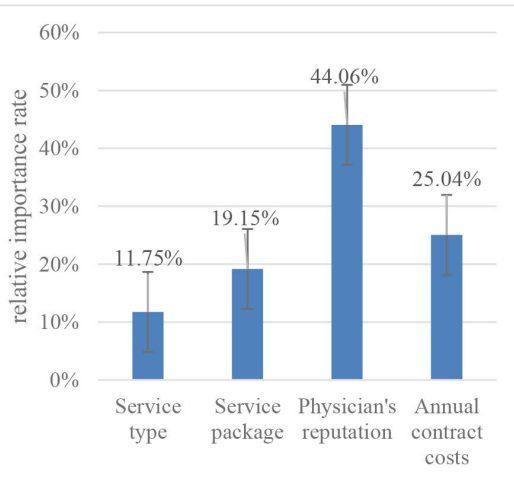

Figure 3 Relative importance of the attributes within each latent class and at the mean.

Although the rural elderly preferred home visit compared with clinic visit, this attribute was the least important which is consistent with those from previous studies. ${ }^{43}$ Some expressed concerns about home visit, including the lack of appropriate medicine provided as well as the lack of relationship with the physicians. They also worried that home visit would reveal their poor physical health to others. Therefore, policymakers could focus on improving the quality of services provided rather than a wider range of service types.

The heterogeneous nature of preferences is an important consideration for policymakers who strive to improve the delivery of personalised primary healthcare services. In this study, gender, age, education, self-reported health status and the number of chronic diseases were identified as important indicators of that heterogeneity. Results from previous studies were consistent with our findings. ${ }^{46-49}$ Healthy older men with lower education levels who did not have chronic diseases were more likely to focus on the quality of the services they chose. However, younger women with chronic diseases and who had higher levels of education prioritised service types and their costs. Thus, efforts should be made to improve the quality of FDCS, make the costs of service reasonable and provide personalised service types to the elderly patients with different characteristics.

\section{CONCLUSION}

Our study suggests that the reputation of the physician could be one of the most important factors for elderly patients in their choice of FDCS. The findings suggest a need to strengthen the training of the family doctor team to meet the potential demand for their services. Particular attention should be paid to developing the doctors' medical skills and doctor-patient communication skills as ways to improve service quality. Annual contract costs and the service package options could also be important factors in deciding to utilise FDCS.

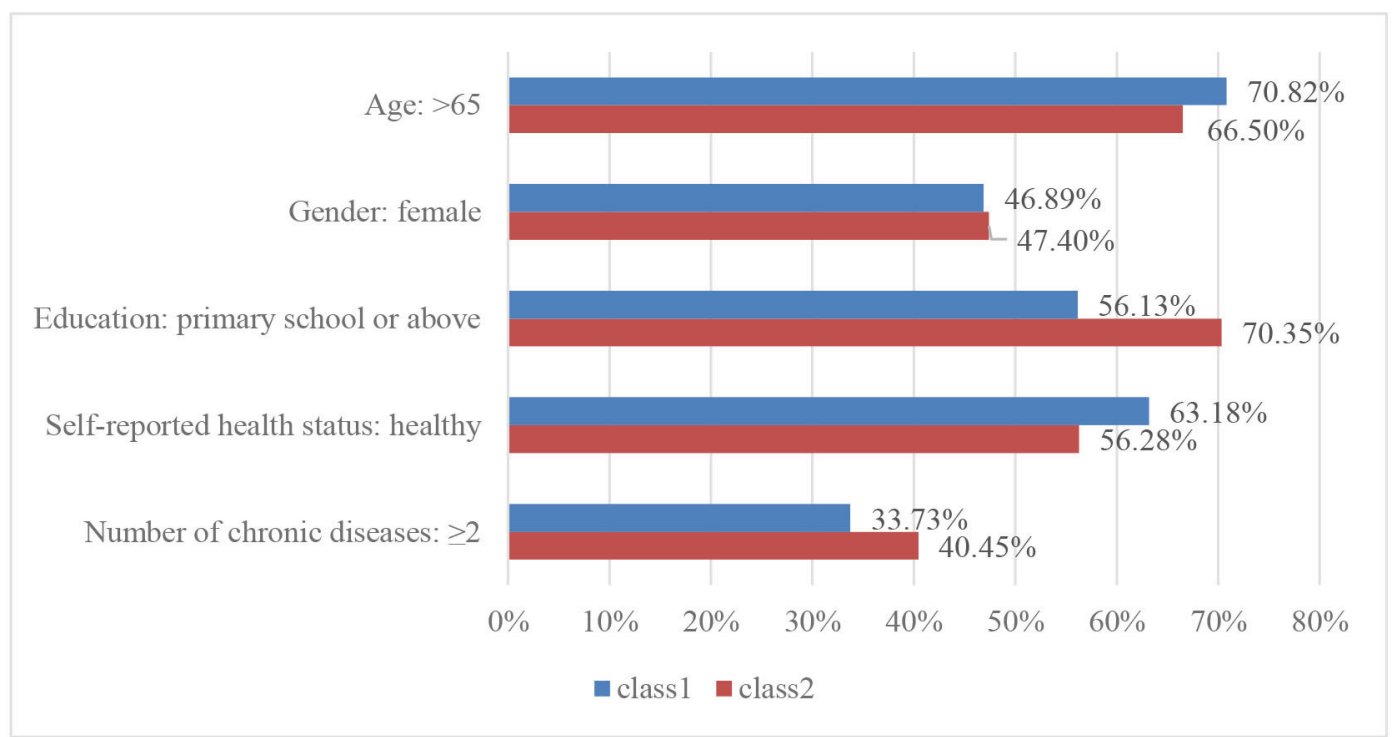

Figure 4 Profile of latent class membership for each class. Note: reference: age $\leq 65$; gender=male; education=no school education; self-reported health status=unhealthy; number of chronic diseases $\leq 1$. $\%$ : the posterior probability of being assigned to a class. 


\section{LIMITATIONS}

The research team have made extensive efforts to ensure the quality of data. Only 11 of the participants failed the rationality test suggesting the methods implemented were effective and participants were overall engaged with the choice tasks. Nevertheless, this study still has several limitations. First, we were unable to include more attributes because of the limitations inherent to a DCE; the total number of attributes and levels that could be reasonably included while maintaining respondent comprehension and data quality was limited. ${ }^{50}$ Second, the reliance on self-reported data created the risk of hypothetical bias. Third, the quality of the data may be affected by fatigue and cognitive constraints since the participants are the elderly with chronic conditions and a low education level. Fourth, this study only estimated the preference of rural elderly for the FDCS in a single province of China. Expanding the research to other provinces and undertaking comparison between rural and urban areas are warranted.

Acknowledgements The authors would like to thank all the interviewers and participants who support the study.

Contributors $\mathrm{CW}$ and $Y G$ are joint first authors. $\mathrm{LW}$ and $Y G$ conceptualised and designed the study. CW, YG, MG and LW conducted the analysis and drafted the manuscript. LZ, YZ and RZ conducted the survey. LW is responsible for the overall content as the guarantor.

Funding This work was funded by the MOE (Ministry of Education in China) Project of Humanities and Social Sciences (grant no. 20YJCZH157) and Young Talents Project of School of Health Service Management of Anhui Medical University (grant no. WGRC201901).

Map disclaimer The depiction of boundaries on this map does not imply the expression of any opinion whatsoever on the part of BMJ (or any member of its group) concerning the legal status of any country, territory, jurisdiction or area or of its authorities. This map is provided without any warranty of any kind, either express or implied.

Competing interests None declared.

Patient consent for publication Consent obtained directly from patient(s).

Ethics approval This study involves human participants. This research project was approved by the Ethics Committee of Anhui Medical University (No: 2020H011). Participants gave informed consent to participate in the study before taking part.

Provenance and peer review Not commissioned; externally peer reviewed.

Data availability statement Data are available upon reasonable request.

Supplemental material This content has been supplied by the author(s). It has not been vetted by BMJ Publishing Group Limited (BMJ) and may not have been peer-reviewed. Any opinions or recommendations discussed are solely those of the author(s) and are not endorsed by BMJ. BMJ disclaims all liability and responsibility arising from any reliance placed on the content. Where the content includes any translated material, BMJ does not warrant the accuracy and reliability of the translations (including but not limited to local regulations, clinical guidelines, terminology, drug names and drug dosages), and is not responsible for any error and/or omissions arising from translation and adaptation or otherwise.

Open access This is an open access article distributed in accordance with the Creative Commons Attribution Non Commercial (CC BY-NC 4.0) license, which permits others to distribute, remix, adapt, build upon this work noncommercially, and license their derivative works on different terms, provided the original work is properly cited, appropriate credit is given, any changes made indicated, and the use is non-commercial. See: http://creativecommons.org/ licenses/by-nc/4.0/.

ORCID iD

Lidan Wang http://orcid.org/0000-0002-8668-1358
REFERENCES

1 Ellner AL, Phillips RS. The coming primary care revolution. J Gen Intern Med 2017;32:380-6.

2 Jiang S, Gu Y, Yang F, et al. Tertiary hospitals or community clinics? An enquiry into the factors affecting patients' choice for healthcare facilities in urban China. China Economic Review 2020;63:101538.

3 Liu Y, Zhong L, Yuan S, et al. Why patients prefer high-level healthcare facilities: a qualitative study using focus groups in rural and urban China. BMJ Glob Health 2018;3:e000854.

4 Chen Z. Launch of the health-care reform plan in China. Lancet 2009;373:1322-4.

5 Yuan S, Wang F, Li X, et al. Facilitators and barriers to implement the family doctor contracting services in China: findings from a qualitative study. BMJ Open 2019;9:e032444.

6 Wu D, Lam TP, Lam KF, et al. Health reforms in China: the public's choices for first-contact care in urban areas. Fam Pract 2017;34:cmw133-200.

7 Jia E, Gu Y, Peng Y, et al. Preferences of patients with noncommunicable diseases for primary healthcare facilities: a discrete choice experiment in Wuhan, China. Int J Environ Res Public Health 2020;17 doi:10.3390/ijerph17113987

8 Liu Y, Kong Q, Wang S, et al. The impact of hospital attributes on patient choice for first visit: evidence from a discrete choice experiment in Shanghai, China. Health Policy Plan 2020;35:267-78.

9 Liu Y, Kong Q, de Bekker-Grob EW. Public preferences for health care facilities in rural China: a discrete choice experiment. Soc Sci Med 2019;237:112396.

10 Huang JL, Liang $\mathrm{H}$, Zhang YM. Promoting the localization dilemma and strategy for the family doctor system: a case study of Hongkou district, Shanghai. Chinese J Health Policy 2016.

11 Jiang-Jiang HE, Yang YH, Zhang TY. Progress and bottlenecks of family doctor system in Shanghai. Chinese J Health Policy 2014.

12 Liang H, Xiao-Lin HE. The Changning model in the exploration and reform of Chinese family doctor system. Chinese $J$ Health Policy 2017.

13 Liu S, Liu Y, Zhang T, et al. The developing family doctor system: evidence from the progress of the family doctor signing service from a longitudinal survey (2013-2016) in Pudong new area, Shanghai. BMC Fam Pract 2021;22:11.

14 Pan YH, Liu D, Cao HT. SWOT analysis on the implementation of family physician system in Shanghai. Chinese Gen Pract 2012;15:1146-8.

15 Li L, Zhong C, Mei J, et al. Effect of family practice contract services on the quality of primary care in Guangzhou, China: a cross-sectional study using PCAT-AE. BMJ Open 2018;8:e021317.

16 Wang LC, Min GE, Jiang P. Community residents' awareness and willingness towards contractual services from family doctors. Chinese Gen Pract 2018.

17 Wei LU, Zhang YM, Liang $\mathrm{H}$. The performance evaluation based on the demand side of the family doctor contract service: a focus on chronic diseases. Chinese J Health Policy 2016.

18 Zheng Q, Shi L, Pang T, et al. Utilization of community health care centers and family doctor contracts services among community residents: a community-based analysis in Shenzhen, China. BMC Fam Pract 2021;22:100.

19 Hou J, Jun LU, Qiao L. Exploration of implementing contractual service relationship between family doctor and residents in rural communities. Chinese Primary Health Care 2014.

20 Li W, Li J, Fu P, et al. Family characteristics associated with rural households' willingness to renew the family doctor contract services: a cross-sectional study in Shandong, China. BMC Public Health 2021;21:1282.

21 Fu P, Wang Y, Liu S, et al. Analysing the preferences for family doctor contract services in rural China: a study using a discrete choice experiment. BMC Fam Pract 2020;21:148.

22 Clark MD, Determann D, Petrou S, et al. Discrete choice experiments in health economics: a review of the literature. Pharmacoeconomics 2014;32:883-902.

23 de Bekker-Grob EW, Ryan M, Gerard K. Discrete choice experiments in health economics: a review of the literature. Health Econ 2012;21:145-72.

24 Oliver D, Deal K, Howard M, et al. Patient trade-offs between continuity and access in primary care interprofessional teaching clinics in Canada: a cross-sectional survey using discrete choice experiment. BMJ Open 2019;9:e023578.

25 Zhu J, Li J, Zhang Z, et al. Exploring determinants of health provider choice and heterogeneity in preference among outpatients in Beijing: a labelled discrete choice experiment. BMJ Open 2019;9:e023363.

$26 \mathrm{Gu}$ Y, Lancsar E, Ghijben P, et al. Attributes and weights in health care priority setting: a systematic review of what counts and to what extent. Soc Sci Med 2015;146:41-52. 
27 Reed Johnson F, Lancsar E, Marshall D, et al. Constructing experimental designs for discrete-choice experiments: report of the ISPOR conjoint analysis experimental design good research practices task force. Value Health 2013;16:3-13.

28 OECD. According to the organization for economic co-operation and development (OECD) data, 2019. Available: https://data.oecd.org/ conversion/exchange-rates.htm [Accessed 30 Mar 2021]

29 Johnson P, Bancroft T, Barron R, et al. Discrete choice experiment to estimate breast cancer patients' preferences and willingness to pay for prophylactic granulocyte colony-stimulating factors. Value Health 2014;17:380-9.

30 Campbell D, Erdem S. Including opt-out options in discrete choice experiments: issues to consider. Patient 2019;12:1-14.

31 Tervonen T, Schmidt-Ott T, Marsh K, et al. Assessing rationality in discrete choice experiments in health: an investigation into the use of dominance tests. Value Health 2018;21:1192-7.

32 Fifer S, Rose J, Greaves S. Hypothetical bias in stated choice experiments: is it a problem? and if so, how do we dea with it? Transportation Research Part A: Policy and Practice 2014;61:164-77.

33 Greene WH, Hensher DA. A latent class model for discrete choice analysis: contrasts with mixed logit. Transportation Research Part B: Methodological 2003;37:681-98.

34 Hole AR. Modelling heterogeneity in patients' preferences for the attributes of a general practitioner appointment. $J$ Health Econ 2008;27:1078-94.

35 Hong IY. Iclogit2: an enhanced command to fit latent class conditional logit models. Stata J 2020;20:405-25.

36 Marang-van de Mheen PJ, Dijs-Elsinga J, Otten W, et al. The relative importance of quality of care information when choosing a hospital for surgical treatment: a hospital choice experiment. Med Decis Making 2011;31:816-27.

37 Johnson FR, Mohamed AF, Özdemir S, et al. How does cost matter in health-care discrete-choice experiments? Health Econ 2011;20:323-30.

38 Hess S, Benakiva M, Gopinath D. Advantages of latent class models over continuous mixture models in capturing heterogeneity 2008.

39 Wu S, Zhao Y, Cao Z. Study on the contract service system of family doctors. 2017:(In Chinese).
40 Huang J, Lu W, Wang L, et al. A preliminary effect analysis of family doctor and medical insurance payment coordination reform in Changning district of Shanghai, China. BMC Fam Pract 2019;20:60.

41 Huang J, Zhang T, Wang L, et al. The effect of family doctorcontracted services on noncommunicable disease self-management in Shanghai, China. Int J Health Plann Manage 2019;34:935-46.

42 Nordin N, Mohd Hairon S, Yaacob NM, et al. Effects of family doctor concept and doctor-patient interaction satisfaction on glycaemic control among type 2 diabetes mellitus patients in the Northeast region of Peninsular Malaysia. Int J Environ Res Public Health 2020;17:1. doi:10.3390/ijerph17051765

43 Shang $\mathrm{X}$, Huang $\mathrm{Y}, \mathrm{Li}$ Bi'e, et al. Residents' awareness of family doctor contract services, status of contract with a family doctor, and contract service needs in Zhejiang Province, China: a cross-sectional study. Int J Environ Res Public Health 2019;16:1. doi:10.3390/ ijerph16183312

44 Fan X, Meng F, Wang D, et al. Perceptions of traditional Chinese medicine for chronic disease care and prevention: a cross-sectional study of Chinese hospital-based health care professionals. BMC Complement Altern Med 2018;18:209.

45 Jiang $\mathrm{M}$, Zhang $\mathrm{C}$, Cao $\mathrm{H}$, et al. The role of Chinese medicine in the treatment of chronic diseases in China. Planta Med 2011;77:873-81.

46 Sun X, Meng H, Ye Z, et al. Factors associated with the choice of primary care facilities for initial treatment among rural and urban residents in southwestern China. PLoS One 2019;14:e0211984.

47 Huang J, Liu S, He R, et al. Factors associated with residents contract behavior with family doctors in community health service centers: a longitudinal survey from China. PLoS One 2018;13:e0208200.

48 Liu Y, Kong Q, Yuan S, et al. Factors influencing choice of health system access level in China: a systematic review. PLoS One 2018;13:e0201887.

49 Peng $\mathrm{Y}$, Jiang $\mathrm{M}$, Shen $\mathrm{X}$, et al. Preferences for primary healthcare services among older adults with chronic disease: a discrete choice experiment. Patient Prefer Adherence 2020;14:1625-37.

50 Bridges JFP, Hauber AB, Marshall D, et al. Conjoint analysis applications in health--a checklist: a report of the ISPOR good research practices for conjoint analysis task force. Value Health 2011;14:403-13. 